\title{
The cost:benefit ratio of acute intervention for myocardial infarction: Results of a prospective, matched pair analysis
}

\begin{abstract}
Parallel to the increased acceptance of intervention for acute myocardial infarction, there has been a decrease in financial resources and reimbursement. To ascertain the relative cost to benefit of intervention, we evaluated 78 matched pairs of acute myocardial infarction patients from a prospective data base of 507 consecutive patients presenting with infarction from May 1986 to July 1987. The pairs were matched for age (mean 61 years), sex (68\% male), and infarct location ( $43 \%$ anterior). Intervention (thrombolytics and/or percutaneous transluminal coronary angioplasty [PTCA]) was only applied to patients at less than 6 hours from symptom onset. Nonintervention patients were subsequently considered for angiography and revascularization (PTCA, coronary artery bypass grafting [CABG]) based on clinical criteria. Clinical outcome was evaluated by in-hospital mortality and uncomplicated status (free of angina, heart failure, or arrhythmias) at $\mathbf{7 2}$ hours. Intervention was associated with decreased mortality (5.3\% versus $13 \%, p=0.16)$ and increased uncomplicated course ( $43 \%$ versus $19 \%, p<0.001)$ as compared with patients not receiving intervention. Hospital procedures for the intervention and nonintervention group were as follows: diagnostic cardiac catheterization ( $99 \%$ versus $51 \%$ ); PTCA (60\% versus $0 \%)$; and CABG (14\% versus $19 \%)$, respectively. The mean cumulative hospital and professional charges were $\$ 31,684$ for the intervention group and $\$ 29,022$ for the nonintervention group $(p=0.50)$. In conclusion, despite the potential marked incremental expense of technology associated with intervention for acute myocardial infarction, this analysis demonstrates that benefit in clinical outcome can be derived without substantially increased costs. (AM HEART J 1989;118:878.)
\end{abstract}

Anthony T. Chapekis, MD, Karen Burek, RN, and Eric J. Topol, MD. Ann Arbor, Mich.

Evidence continues to mount supporting the efficacy of early reperfusion therapy with either thrombolysis or angioplasty in the treatment of evolving myocardial infarction. Several recent, large-scale, randomized clinical trials have demonstrated decreased mortality, improved left ventricular function, and limitation of infarct size in patients treated with thrombolytic agents. ${ }^{1-7}$ Angioplasty appears to have a limited role in the immediate management of myocardial infarction treated with thrombolytic therapy. ${ }^{8-10}$ However, emergency angioplasty may ultimately find its place in the treatment of persistently occluded arteries despite thrombolytic ther-

From the Division of Cardiology, Department of Internal Medicine, University of Michigan Medical Center.

Received for publication May 22, 1989; accepted July 7, 1989.

Reprint requests: Eric J. Topol, MD, Division of Cardiology, University of Michigan Medical Center, B1 F245, 1500 East Medical Center Drive, Ann Arbor, MI 48109-0022.

4/1/15204 apy, or for such patients with contraindications to thrombolytic therapy. ${ }^{11}$

Despite these improvements in the treatment of myocardial infarction, certain disadvantages of reperfusion therapy are evident. These include the incremental risks of bleeding, recurrent ischemic events, and higher technologic costs. The economics of reperfusion are especially pertinent in this era of declining resources and reimbursement. In-hospital costs of treatment are related to a variety of factors, including professional services, laboratory fees, patient mix, complications, and length of hospital stay. ${ }^{12}$ These variables have been evaluated using statistical models of treatment strategies with conclusions showing the incremental cost per additional survivor. ${ }^{13-16}$ Vermeer et al. ${ }^{15}$ have published calculated economic data applying estimated charges, comparing standard treatment of infarction to thrombolysis using intracoronary streptokinase and acute angioplasty as necessary. However, no prospective 
cost analysis of intravenous thrombolysis that used actual hospital charges in a patient population has been performed. Thus the purpose of this study was to define the clinical outcome, relative charges, and cost per additional survivor in a series of infarct patients treated with intervention versus nonintervention strategies.

\section{METHODS}

Patient population. All patients presenting to the University of Michigan Medical Center from May 21, 1986, through July 23,1987 , with acute myocardial infarction formed the data base in this study. ${ }^{17}$ Criteria necessary for inclusion included onset of symptoms within 24 hours, electrocardiographic and/or enzymatic evidence of infarction. Enzyme-positive infarction was defined as creatine kinase MB fraction greater than $3 \%$ of total serum level. Patients in the data base included those with in-hospital infarction, provided this was not related to coronary angioplasty.

From the total population, a study group was selected, based on a matched pair analysis of patients receiving acute intervention versus nonintervention therapies. The pairs were matched for infarct location, followed by gender, followed by age in order to maximize the number of pairs with matched variables. Intervention was only applied to patients at less than 6 hours time from symptom onset, and was defined as attempted reperfusion using one of three methods that were employed on a nonrandom basis. These were intravenous thrombolytic therapy alone, direct coronary angioplasty, or a combination of both. All patients having acute intervention had an emergency cardiac catheterization.

Decision to perform acute intervention was individualized; however, entry criteria closely paralleled that of previously reported studies ${ }^{8,17}$ : (1) Age less than or equal to 75 years; (2) Chest discomfort for greater than 20 minutes and less than 4 hours, unrelieved by nitroglycerin, or severe, ongoing chest pain less than or equal to 6 hours in duration; (3) Greater than $1 \mathrm{~mm}$ of ST elevation in two contiguous electrocardiographic (ECG) leads; (4) No bleeding predisposition, recent trauma, stroke or surgery; (5) No prior coronary artery bypass graft (CABG) surgery or previous myocardial infarction in the same territory; and (6) $\mathrm{Ab}$ sence of cardiogenic shock, as defined by systolic blood pressure below $85 \mathrm{~mm} \mathrm{Hg}$ unresponsive to volume expansion.

Clinical outcome between groups was evaluated using 10-day mortality and a measure of clinical status at 72 hours. Patients were considered uncomplicated if none of the following were present: (1) angina, defined as rest pain lasting more than 20 minutes, associated with ECG changes; (2) congestive heart failure, diagnosed by a new requirement for digoxin and furosemide therapy or bibasilar rales half way up the posterior fields, or a ventricular gallop; (3) systolic blood pressure less than $90 \mathrm{~mm} \mathrm{Hg}$; (4) left ventricular ejection fraction less than $35 \%$, as determined by left ventriculography or radionuclide angiography; (5) higher than Lown class 3 ventricular arrhythmias; and (6) high-grade (Mobitz II or third-degree) atrioventricular block.

Hospital and professional charges. All hospital and professional charges were prospectively collected from the hospital hilling records for each patient. These included intensive care unit, room, laboratory, nuclear medicine, catheterization laboratory, and respiratory therapy charges. Medication and subsequent outpatient charges were not included. Included in the hospital charges was an additional $\$ 2,000$ for those patients receiving tissue plasminogen activator (t-PA) on experimental protocol. In addition, if a patient underwent a procedure purely for research purposes only, (e.g., additional functional tests, 7 to 10-day follow-up catheterization in an asymptomatic patient) these charges were omitted from the analysis.

Data analysis. Entry of data from the case report form was performed by a research assistant with quality control provided by the biostatistical staff. Analysis of the data was based on a matched pair analysis of intervention and nonintervention groups with regard to clinical and economic outcome. Comparison was made by chi square or by Fisher's exact test for discrete variables and by $t$ test or analysis of variance for continuous characteristics. Data in text or tabulated form are expressed as means \pm one standard deviation. All reported $p$ values are two-tailed.

\section{RESULTS}

Patient population and types of intervention. A total of 507 patients was included in the data base, with 78 matched pairs drawn from this group for analysis. The baseline characteristics of the matched pairs were as follows: mean age of 61 years, $68 \%$ male, and $43 \%$ having anterior infarct location. The type of reperfusion therapy applied in the intervention group consisted of intravenous thrombolysis only in 27 patients (t-PA in 23, streptokinase in 4), 14 patients underwent coronary angioplasty as the sole method of reperfusion, while 34 patients had combined thrombolysis followed by angioplasty. No attempt at myocardial reperfusion was made in the nonintervention group. The specific reasons included: greater than 6 hours of chest pain in 39 patients, age greater than 75 years in eight patients, 25 patients had miscellaneous medical or surgical contraindications to intervention, two patients had psychiatric contraindications, three patients refused, and one patient had known coronary anatomy that did not require intervention.

Procedures performed and clinical outcome. The diagnostic and revascularization procedures performed in the intervention versus the nonintervention group were as follows: catheterizations $99 \%$ versus $51 \%$, coronary angioplasty $60 \%$ versus $0 \%$, and bypass surgery $14 \%$ versus $19 \%$. The near $100 \%$ diagnostic catheterization rate in the intervention group reflects 
Table I. Results: Cumulative hospital and professional charges

\begin{tabular}{lcrc}
\hline & $\begin{array}{c}\text { Intervention } \\
(n=78)\end{array}$ & $\begin{array}{c}\text { Nonintervention } \\
(n=78)\end{array}$ & $p$ \\
\hline Professional & $\$ 6,005 \pm \$ 3,332$ & $\$ 4,899 \pm \$ 4,220$ & 0.07 \\
Hospital & $\$ 25,679 \pm \$ 22,995$ & $\$ 24,123 \pm \$ 20,805$ & 0.66 \\
Total & $\$ 31,684 \pm \$ 25,583$ & $\$ 29,022 \pm \$ 23,582$ & 0.50 \\
$\quad$ Range & $\$ 10,005-\$ 177,710$ & $\$ 6,078-\$ 140,210$ & \\
Median & $\$ 21,925$ & $\$ 19,249$ & \\
\hline
\end{tabular}

Cost/additional survivor $=\$ 34,600$.

the treatment protocol of the time, that dictated urgent catheterization in all patients. Of particular note is the $50 \%$ of patients in the nonintervention group for whom diagnostic catheterization was performed during the initial hospitalization. In addition, the coronary bypass surgery rates of $14 \%$ in the intervention group and $19 \%$ in the nonintervention group are comparable to the 1-year bypass surgery rates in the randomized study of Vermeer et al. ${ }^{15}$ Clinical outcome was measured by uncomplicated clinical status at 72 hours and by 10 -day mortality. As would be expected from the previously cited trials, patients undergoing acute intervention were significantly more likely to have uncomplicated clinical status (43\% versus $19 \%[p<0.001])$ and improved 10-day mortality $(5.3 \%$ versus $13 \%[p=0.16])$. Coronary care unit days and total hospital stay were not significantly different between the two groups.

Hospital charges. The in-hospital charges for each matched pair group as obtained from the hospital billing records are shown in Table I. The data are broken down into total hospital charges and total professional charges, in addition to the sum of these charges. Although a trend favoring no intervention is apparent, no statistically significant difference between the two groups is demonstrated. The fact that there is no clear cost increase in the intervention group despite the incremental expense of thrombolytics and increased usage of procedures (catheterization and angioplasty) is particularly striking. This can be explained at least in part by the less complicated course and improved survival in the intervention group. Using the six additional survivors in the intervention group and differential charges of $\$ 2600$, the cost per additional survivor can be estimated at $\$ 34,600$.

\section{DISCUSSION}

Complications of acute myocardial infarction contribute a substantial proportion to overall cardiovascular mortality. Recent advances in the early diag- nosis and treatment of myocardial infarction have clearly demonstrated improved survival and clinical outcome. However, a definitive assessment of the relative costs and benefits of intervention therapy has yet to be put forth.

Our study, performed with a matched pair analysis from a large prospectively collected data base of patients with acute myocardial infarction, provides information on actual costs and clinical outcome. These patients were treated primarily with intravenous thrombolytics, acute catheterization, and elective angioplasty. As would be expected from the results of previous trials of intervention in acute infarction, the intervention group was significantly more likely to have an uncomplicated clinical course and lower mortality. Analysis of cumulative charges for the initial hospital stay demonstrated that intervention (including more use of catheterization and percutaneous transluminal coronary angioplasty [PTCA]), did not result in substantially higher total costs. Professional charges, however, did approach statistical significance but were a relatively minor part of the total hospital charges. When we use the six additional survivors and excess mean charges of $\$ 2600$ in the intervention group, the cost per additional survivor can be estimated at $\$ 34,600$ which is in keeping with the findings of previously published studies.

When interpreting these results, comparison to these studies is warranted. Four groups have looked at the issue using the cost per additional survivor as a measure of the cost-to-benefit ratio. Table II lists these studies by author and method by which the cost per additional survivor was obtained. The first three studies-those of Laffel et al., ${ }^{13}$ Steinberg et al., ${ }^{14}$ and Liu et al. ${ }^{16}$ are model-based, using assumptions for outcome based on published knowledge for type of lytic therapy and reocclusion/revascularization management strategy. The assumptions include time to treatment, thrombolytic efficacy, myocardium salvaged, utilization of angioplasty or bypass surgery, and mortality. The estimations werc based on patients receiving t-PA at 4 hours and full use of angioplasty or bypass surgery for aggressive management. Cost estimates in the Laffel et al. and Liu et al. studies were based on current hospital charges at their institutions. Steinberg et al. used Medicare diagnosis-related group reimbursement (Table III) in their model. Estimated cost per additional survivor ranged from $\$ 56,000$ to $\$ 73,000$. The Vermeer study, ${ }^{15}$ that used clinical data and procedural usage from their randomized trial of intracoronary streptokinase versus placebo, with cost estimates calculated retrospec- 
Table II. Published studies of cost effectiveness of myocardial reperfusion

\begin{tabular}{lcccc}
\hline First Author & Ref no. & Derivation & Treatment ${ }^{*}$ & Cost/additional survivor $^{\text {a }}$ \\
\hline Laffel & 13 & Model & t-PA & $\$ 73,000$ \\
Steinberg & 14 & Model & t-PA & $\$ 56,900$ \\
Liu & 16 & Model & t-PA & $\$ 61,000$ \\
Vermeer & 15 & Patient & IC SK & $\$ 49,000$ \\
\hline
\end{tabular}

t-PA, Tissue-type plasminogen activator; IC, intracoronary; SK, streptokinase; PTCA, percutaneous transluminal coronary angioplasty; CABG, coronary artery bypass grafting.

*Treatment strategies include PTCA and CABG.

tively, demonstrates a similar cost per additional survivor. All are within the range of other generally accepted medical therapies. ${ }^{18,19}$

In addition to these estimates of the direct monetary costs, other factors must be considered that perhaps will reflect a "true" cost of intervention. These include the benefit to individual patients in terms of quality of life and their ability to return to fully productive work. From a societal point of view, improved outcomes following acute myocardial infarction are likely to result in less work time lost, improved productivity, and diminished supplemental benefits to families secondary to partial or total disability or death. Finally, the ability of hospitals to support and sustain these technological advancements without further capital investment comes into question.

These results raise some very important and controversial questions. First, why were the total charges at our hospital so high, especially in comparison to standard diagnosis-related group (DRG) reimbursement? We believe this reflects the extreme tertiary character of our institution with charges for routine hospitalization requiring proration for case-mix, training program funding, and prevailing local reimbursement patterns. Second, with an ever greater proportion of elderly patients, how do we continue to provide state of the art care for acute infarction with such significant mismatch between actual costs and Medicare reimbursement? This question will need to be approached from a societal point of view, with experts and legislators making value judgments concerning the cost-to-benefit ratio. Finally, will the possibility of expanding eligibility criteria for intervention, including benefit seen from reperfusion beyond the previously accepted time window of 4 to 6 hours as reported in the Second International Study of Infact Survivors (ISIS-2) trial, ${ }^{2}$ result in a marked change in the cost-to-benefit ratio? Clearly, ongoing assessment of cost and benefits, as standard therapy for myocardial infarction evolves, will thus be required.

Certain limitations of this study are evident. The
Table III. Diagnosis-related groups (DRGs) and 1988 payment rates related to hospitalizations for acute myocardial infarction

\begin{tabular}{ccc}
\hline DRG & \multicolumn{1}{c}{ Description } & FY88 payment rate* \\
\hline 106 & $\begin{array}{l}\text { Coronary bypass with } \\
\text { cardiac catheterization }\end{array}$ & $\$ 17,771$ \\
112 & $\begin{array}{l}\text { Vascular procedures except } \\
\text { major reconstruction }\end{array}$ & $\$ 6,064$ \\
121 & $\begin{array}{l}\text { Circulatory disorders with } \\
\text { AMI and CV }\end{array}$ & $\$ 5,504$ \\
& $\begin{array}{l}\text { complications discharged } \\
\text { alive }\end{array}$ & \\
122 & $\begin{array}{l}\text { Circulatory disorders with } \\
\text { AMI without CV } \\
\text { complications discharged } \\
\text { alive }\end{array}$ & $\$ 3,849$ \\
Circulatory disorders with & AMI, died
\end{tabular}

FY88, 1988 fiscal year; AMI, acute myocardial infarction; CV, cardiovascular.

*Payment rates are Medicare's fiscal year 1988 hospital payment rates for Baltimore metropolitan area hospitals.

use of a matched pair analysis from a prospective data base does not provide the same information as a randomized trial with a "control" nonintervention group. However, with the documented benefits of early reperfusion therapy, such a trial would not now be ethically possible. Costs related to the nonintervention group potentially are skewed, as exclusion from intervention was based on factors (age, duration of infarct, and complicating medical problems) that could increase in-hospital costs. In addition, longterm clinical outcome and mortality information are more relevant to a measure of the cost-to-benefit ratio than in-hospital data.

Despite these limitations of our investigation, several important conclusions can be reached. Intervention will clearly have a continuing role in the treatment of myocardial infarction as the significant benefits on clinical outcome and mortality are well defined. The cost-to-benefit ratio, as analyzed by modeled studies and clinical trials, appears to be within the realm of other generally accepted medical 
treatments such as dialysis for the treatment of endstage renal disease and drug therapy for the treatment of essential hypertension. ${ }^{18,19}$ Finally, until optimal treatment strategies for acute myocardial infarction are refined, including decisions concerning the type of thrombolytic employed, the time window for treatment, the need or lack thereof for early catheterization and/or angioplasty, ${ }^{8,10,20}$ and the timing of hospital discharge following myocardial infarction in selected patient groups ${ }^{17}$ the true costto-benefit ratio of intervention will remain elusive.

\section{REFERENCES}

1. Gruppo Italiano Per Lo Studio Della Streptochi-Nasi Nell'Infarcto Miocardio (GISSI). Effectiveness of intravenous thrombolytic treatment in acute myocardial infarction. Lancet 1986;1:397-401.

2. ISIS-2 (Second International Study of Infarct Survival) Collaborative Group. Randomized trial of intravenous streptokinase, oral aspirin, both, or neither among 17,187 cased of suspected acute myocardial infarction: ISIS-2. Lancet 1988;2:34960 .

3. White HD, Norris RM, Brown MA, Takayama M, Maslowski A, Bass NM, Ormiston JA, Whitlock T. Effect of intravenous streptokinase on left ventricular function and early survival after acute myocardial infarction. N Engl J Med 1987;317: 850-5.

4. Guerci AD, Gerstenblith G, Brinker JA, Chandra NC, Gottlieb SO, Bahr RD, Weiss JL, Shapiro EP, Flaherty JT, Bush DE, Chew PH, Gottlieb SH, Halperin HR, Ouyang P, Walford GD, Bell WR, Fatterpaker AK, Llewellyn M, Topol EJ, Healy B, Siu CO, Becker LC, Weisfeldt ML. A randomized, placebo controlled, double blinded trial of intravenous tissue plasminogen activator for acute myocardial infarction with subsequent randomization to elective coronary angioplasty. N Engl J Med 1987;317:1613-18.

5. The I.S.A.M. Study Group. A prospective trial of intravenous streptokinase in acute myocardial infarction (I.S.A.M.). N Engl J Med 1986;314:1465-71.

6. Simoons ML, Brand MVD, de Zwaan C, Verheug FW, Remme WJ, Serruys PW, Bär F, Res J, Krauss XH, Vermeer F, Lubsen J. Improved survival after early thrombolysis in acute myocardial infarction. Lancet 1985;2:578-82.

7. The TIMI Study Group. The Thrombolysis In Myocardial Infarction (TIMI) trial. N Engl J Med 1985;312:932-6.
8. Topol EJ, Califf RM, George BS, Kereiakes DJ, Abbottsmith CW, Candela RJ, Lee KL, Pitt B, Stack RS. O'Neill WW. A randomized trial of immediate versus delayed elective angio. plasty after intravenous tissue plasminogen activator in acule myocardial infarction. N Engl J Med 1987;317:581 8.

9. Ryan TJ. Angioplasty in acute myocardial infarction: is the balloon leaking? N Engl J Med 1987;317:624-6.

10. Simoons ML, Betriu A, Col .J, von Essen R, Lubsen J, Michel PL, Rutsch W, Schmidt W, Thery C, Vahanian A. Willems GM, Arnold AE, de Bono DP, Dougherty FC, Lambertz $\mathrm{H}$, Meier B, Raynaud P, Sanz GA, Serruys PW, Uebis R, Van de Werf F, Wood D, Verstraete M. Thrombolysis with tissue plasminogen activator in acute myocardial infarction: no ad ditional benefit from immediate percutaneous coronary angioplasty. Lancet 1988;1:197-203.

11. 'I'opol EJ. Direct vs. sequential percutaneous transluminal coronary angioplasty. In: Topol EJ, ed. Acute coronary intervention. New York: A. R. Liss, 1988.

12. Stern RS, Epstein AM. Institutional responses to prospective payment based on diagnosis-related groups: implications for cost, quality and access. N Engl J Med 1985;312:621-7.

13. Laffel GL, Fineberg HV, Braunwald E. A cost-effectiveness model for thrombolysis/reperfusion therapy. J Am Coll Cardiol 1987;10:79B-90B.

14. Steinberg EP. Topol EJ, Sakin JW, Kahane SN, Appel LJ, Powe NR, Anderson GF, Erickson .JE, Guerci AD. Cost and procedure implications of thrombolytic therapy for acute myocardial infarction. J Am Coll Cardiol 1988;12:58A-67A.

15. Vermeer F, Simoons M, de Zwaan C, van Es GA, Verheugt FW, van der Laarse A, van Hoogenhuyze DC, Azar ArJ, van Dalen FJ, Lubsen J, Hugenholtz PG. Cost benefit analysis of early thrombolytic treatment with intracoronary streptokinase. $\mathrm{Br}$ Heart J 1988;59:527-34.

16. Liu P, Floras J, Haq A, Detsky A. Cost-effective evaluation of thrombolytic therapy: comparison of current modalities and identification of critical cost factors-a Canadian perspective [Abstract]. J Am Coll Cardiol 1988;11:186A.

17. 'Topol EJ, Burek K, O’Neill WW, Kewman DG, Kander NH, Shea MJ, Schork A, Kirscht J, Juni JE, Pitt B. A randomized controlled trial of hospital discharge three days after myocardial infarction in the era of reperfusion. $N$ Engl $J$ Med 1988;318:1083-8.

18. Stason WB, Weinstein MC. Allocation of resources to manage hypertension. N Engl J Med 1977;296:732-9.

19. Roberts SD, Maxwcll DR, Gross TL. Cost-effective care of end stage renal disease: a billion dollar question. Ann Intern Med $1980 ; 92: 243-8$.

20. The TIMI Research Group. TIMI-IIa results; immediate versus delayed catheterization and angioplasty following therapy for acute myocardial infarction. JAMA 1988;260:2849-58. 